\title{
Effect of CBC and G-POSS on Tribological Behaviour of Polyamide 6 and Short Glass Fiber Reinforced Polyamide 6 Composites
}

\author{
O. GuL ${ }^{a}$, S. Yilmaz ${ }^{b}$, T. Yilmaz ${ }^{a, *}$ \\ ${ }^{a}$ Kocaeli University, Mechanical Engineering Department, Umuttepe Campus, 41380 Izmit, Turkey \\ ${ }^{b}$ Kocaeli University, Ali Rıza Veziroğlu Vocational High School, Arslanbey Campus,41285 Izmit, Turkey \\ In this study, effect of glycidylisobutyl oligomeric silsesquioxane (G-POSS) and 1.1'-carbonyl-bis-caprolactam \\ (CBC) (1 wt.\%) on the friction and wear performance of polyamide 6 (PA6) and short glass fiber (SGF) (10 and \\ 20 wt.\%) reinforced PA6 composites were investigated. Adhesive wear tests were carried out by using a tribometer \\ in block-on-ring configuration (ASTM G77), in sliding conditions, without lubricants and in air. Tests were carried \\ out at sliding speed of $1.6 \mathrm{~m} / \mathrm{s}(511 \mathrm{rpm})$ and applied load values of 25,50 and $75 \mathrm{~N}$. Wear rate was calculated \\ using weight loss per unit sliding distance. The results showed that, the friction force increases with the increasing \\ load. It was found that the wear resistance of PA6 improved considerably after doping with CBC.
}

DOI: $10.12693 /$ APhysPolA.127.1121

PACS: 81.40.Pq, 81.05.Qk

\section{Introduction}

Polyamides, especially polyamide 6 and polyamide 66 are the most used engineering materials, which are preferred as materials for bearings, bolts, gaskets, cams, gears etc., because of their easy availability, high strength/weight ratio, good combination of strength along with tribological performance, high barrier properties to liquids and gases, excellent resistance to mechanical fatigue, and low cost [1-4].

Polyamide has good wear resistance, low coefficient of friction and toughness. So it is an ideal replacement for a wide variety of materials from metal to rubber [5].

Tribological applications of polymeric materials have been expanded considerably over the last few decades, because the demands for weight and cost savings have forced the replacement of metallic components with polymer based materials [6].

Usage of polyamide reduces lubrication requirements and the corrosion, and still improves the wear resistance. The friction and wear behavior of polyamides are fairly good under dry sliding conditions. The importance of the tribological properties of polymer composites encourages researchers to study the wear behavior and to improve the wear resistance of polymeric materials. The load, sliding speed and sliding distance are very influential parameters on the wear rate of the polyamide composites [7-11].

In present study, adhesive wear of PA6 and short glass fiber (SGF) reinforced PA6 composites, compatibilized with carbonyl bis caprolactam (CBC) and

* corresponding author; e-mail: taner.yilmaz@kocaeli.edu.tr
Glycidylisobutyl-POSS were investigated. The samples were evaluated by means of wear and friction methods.

\section{Materials and methods}

Polyamide 6 (PA6) matrix was supplied in granule form from EPSAN Company, Turkey. Silane surface treated SGF, used as the reinforcing material, was supplied from Cam Elyaf A.S., Turkey, under the trade name of PA1. The chain extender $\mathrm{CBC}$ was received in white fine granule form from DSM, Netherlands. G-POSS was provided by Hybrid Plastics, USA.

PA6 based composites were prepared via melt blending in a twin-screw micro-compounder ( $15 \mathrm{ml}$, DSM Xplore, The Netherlands) at barrel temperature of $240{ }^{\circ} \mathrm{C}$, with a screw speed of $100 \mathrm{rpm}$. PA6 was dried in oven at $80{ }^{\circ} \mathrm{C}$ for $12 \mathrm{~h}$ under vacuum before the mixing process. G-POSS and CBC were added separately in quantity of $1 \mathrm{wt} . \%$ to the pure PA6 and to SGF-reinforced (10 and 20 wt.\%) PA 6. Each composition was kept in the barrel for mixing period of $3 \mathrm{~min}$. At the end of the mixing period, the melt was transferred to injectionmolding device. The injection and holding pressures were set to 10 bars. Melt and mold temperatures were $240{ }^{\circ} \mathrm{C}$ and $50^{\circ} \mathrm{C}$, respectively. The samples are abbreviated according to their content. For example PA $6+\mathrm{SGF} 10+\mathrm{G} 1$ indicates that composite containing $10 \mathrm{wt} \% \mathrm{SGF}$ and 1 wt.\% G-POSS. Wear samples having dimensions of $13 \times 10 \times 2 \mathrm{~mm}^{3}$, were prepared by cutting from Polyamide 6 composite.

Tribological investigation was performed on "Plint" multipurpose friction and wear tester, according to ASTM G 77 standards. The dry sliding wear resistance tests of the samples were carried out by using a tribometer in block-on-ring type configuration, in sliding conditions, without lubricants and in air. The wear machine was stopped at sliding distance of $1000 \mathrm{~m}$ and the wear 
amount was recorded. Frictional force in each of 48 meters was also recorded. AISI 52100 steel with diameter of $60 \mathrm{~mm}$ and thickness of $4 \mathrm{~mm}$ was used as the ring material. The ring material was heated to $880^{\circ} \mathrm{C}$ and after treatment for 60 min the material was hardened to 62 HRC by quenching. The wear tests with the sliding distance of $1000 \mathrm{~m}$ were carried out at room temperature, sliding speed of $511 \mathrm{rpm}(1.6 \mathrm{~m} / \mathrm{s})$ and normal loads of 25, 50 and 75 N. Frictional force measurements were done using a force transducer.

\section{Results and discussion}

Mass loss of PA6, SGF reinforced PA6 and $\mathrm{CBC} / \mathrm{G}-$ POSS doped PA6 composites at various loading rates is shown in Fig. 1. The wear resistance of the PA6 composite has increased considerably after incorporation of $\mathrm{CBC}$ into the PA6 matrix. It can be seen in Fig. 1 that $\mathrm{CBC}$ is an effective factor to improve wear resistance of matrix material. Figure 1 also shows that the wear resistance of the PA6 decreases with the increasing SGF reinforcement.
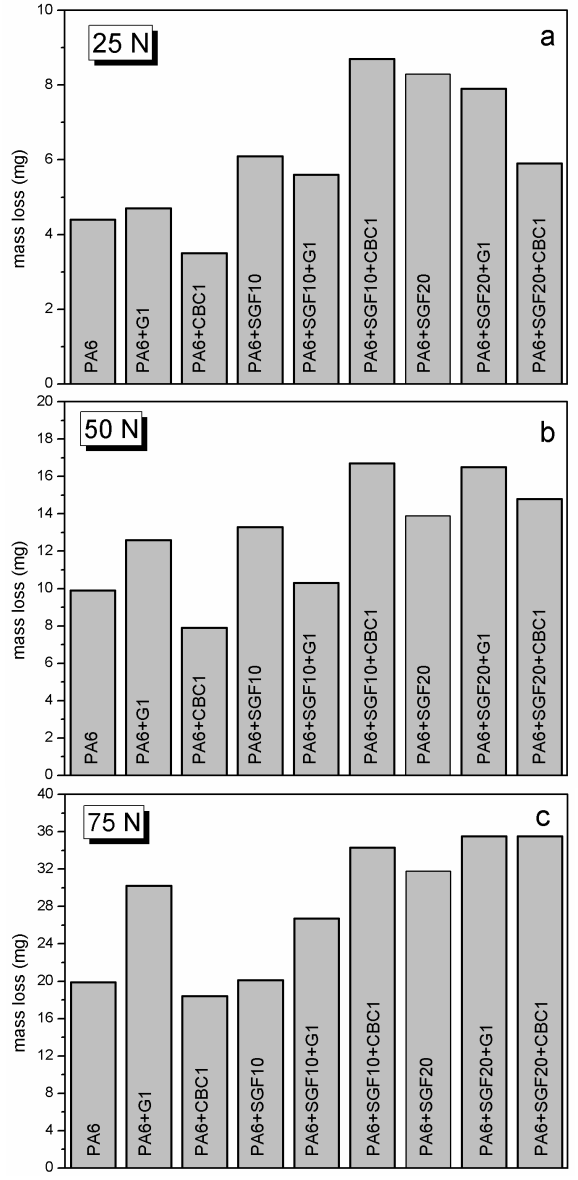

Fig. 1. Mass loss at sliding distance of $1000 \mathrm{~m}$ under a load of a) $25 \mathrm{~N}$, b) $50 \mathrm{~N}$, c) $75 \mathrm{~N}$.

It was noted that the highest mass loss values were obtained under $75 \mathrm{~N}$ wear load for all samples (Fig. 1c). As seen in Fig. 1, wear amount increased with the increase of sliding distance. The mass loss results show that wear occurs generally more slowly under the load of $25 \mathrm{~N}$ (Fig. 1a) than under the loads of $50 \mathrm{~N}$ (Fig. 1b) and $75 \mathrm{~N}$ (Fig 1c). Under wear load of $25 \mathrm{~N}$, the wear resistance of the $10 \mathrm{wt} . \%$ short fiber and $1 \mathrm{wt} . \% \mathrm{CBC}$ reinforced PA6 composites, increases about twofold, when compared with the pure PA6 material and 1.5 times, when compared 10 wt.\% short fiber and 1 wt.\% G-POSS doped PA6 (Fig. 1a).
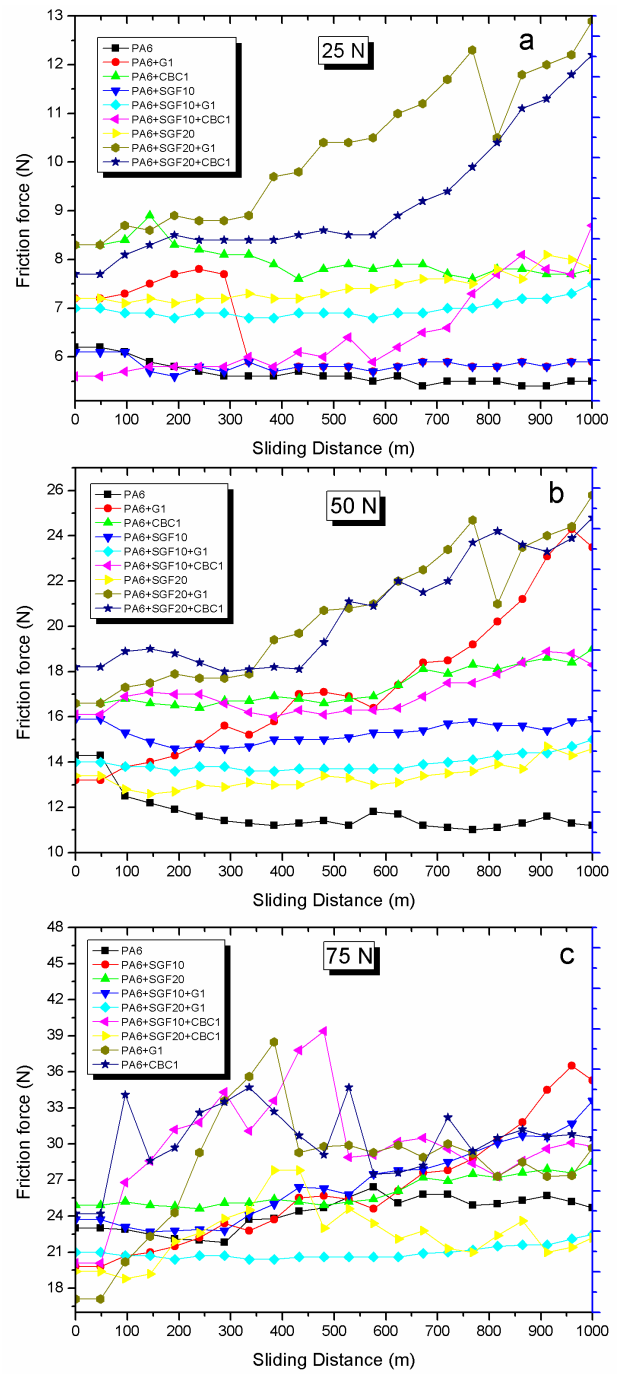

Fig. 2. Friction forces at normal load of a) $25 \mathrm{~N}$, b) $50 \mathrm{~N}, \mathrm{c}) 75 \mathrm{~N}$.

Figure 2 shows the friction force measurements along the sliding distance (total sliding distance is $1000 \mathrm{~m}$ ) of PA6 and its composites under normal loads, dry sliding conditions, against the AISI 52100 steel. It was noted that the highest friction force values were obtained under wear load of $75 \mathrm{~N}$ for all samples (Fig. 2c). Under the normal load of $50 \mathrm{~N}$ all samples had the friction force values between 12 and $26 \mathrm{~N}$ (Fig. $2 \mathrm{~b}$ ). Under the normal load of $25 \mathrm{~N}$, friction forces decreased down to range between 8 and $10 \mathrm{~N}$ (Fig. 2a). The increase in mass loss of materials results in an increase in friction forces. The friction force is influenced by the normal load. The fric- 
tion coefficient of the material at normal load of $25 \mathrm{~N}$ (Fig. 2a) was about half of that found with normal load of $50 \mathrm{~N}$ (Fig. 2b). Pure PA6 composites exhibited a lower friction force, compared to other samples. Figure 2, also shows the effect of normal loads on the friction force of PA6 and its composites under the dry sliding condition. Under dry sliding, the friction force of PA6 and its composites increased with the increasing normal load. With the increasing normal load, the contact temperature between PA6 block and AISI 52100 ring generally increases due to the frictional heat, which results in an increase in the contact area, and hence the friction force of PA6 and PA6 composites increases.

\section{Conclusions}

The influence of incorporation of CBC and G-POSS into PA6 and SGF-reinforced PA6 composites, as a function of normal load and sliding distance, on the friction and wear of PA6 has been studied by using a blockon-ring tribometer. Following conclusions can be drawn from the results:

1. CBC addition has improved the sliding wear resistance of PA6 against the AISI 52100 ring.

2. Short fiber reinforcement of PA6 has decreased the wear resistance of PA6 materials for both 10 and $20 \mathrm{wt} . \%$.
3. G-POSS incorporation into 10 wt.\% SGFreinforced PA6 composite has increased the wear resistance of composites for 25 and $50 \mathrm{~N}$ wear loads.

4. 1 wt.\% CBC in PA6 has significantly decreased the friction force.

\section{References}

[1] S.N. Kukureka, C.J. Hooke, M. Rao, P. Liao, Y.K. Chen, Tribology International 32, 107 (1999).

[2] S.S. Kim, M.W. Shin, H. Jang, Wear 274-275, 34 (2012).

[3] H. Unal, A. Mimaroglu, Wear 289, 132 (2012).

[4] Y.-L. You, D.-X. Li, G.-J. Si, X. Deng, Wear 311, 57 (2014).

[5] E. Basavaraj, B. Ramaraj, J.-H. Lee, Siddaramaiah, Materials Chemistry and Physics 138, 658 (2013).

[6] M.T. Demirci, H. Duzcukoglu, Materials and Design 57, 560 (2014).

[7] L. Chang, Z. Zhang, H. Zhang, A.K. Schlarb, Composites Science and Technology 66, 3188 (2006).

[8] G. Srinath, R. Gnanamoorthy, Composites Science and Technology 67, 399 (2007).

[9] H. Meng, G.X. Sui, G.Y. Xie, R. Yang, Composites Science and Technology 69, 606 (2009).

[10] J. Li, Current Applied Physics 9, 1445 (2009).

[11] J.W. Kim, H. Jang, J.W. Kim, Wear 309, 82 (2014). 